\title{
Bearing Capacity Map for An-Najaf and Kufa Cities Using GIS
}

\author{
Laheab A. Jasem Al-Maliki' ${ }^{1}$, Sohaib Kareem Al-Mamoori², Khaled El-Tawel ${ }^{3}$, \\ Hussain M. Hussain ${ }^{4}$, Nadhir Al-Ansari ${ }^{5}$, Mohammed Jawad Al Ali'
}

\author{
${ }^{1}$ Department of Hydraulic Engineering Structures, Faculty of Water Resources Engineering, Green \\ University of Al Qasim, Baghdad, Iraq \\ ${ }^{2}$ Department of Environmental Planning, Faculty of Physical Planning, University of Kufa, Najaf, Iraq \\ ${ }^{3}$ Lebanese University, Faculty of Engineering, Beirut, Lebanon \\ ${ }^{4}$ Remote Sensing Center, University of Kufa, Najaf, Iraq \\ ${ }^{5}$ Department of Civil, Environmental and Natural Resources Engineering, Lulea University of Technology, Lulea, Sweden \\ ${ }^{6}$ Department of Environmental Planning, Faculty of Physical Planning, University of Kufa, Najaf, Iraq \\ Email: laheab.almaliki@wrec.uoqasim.edu.iq, sohaib.almamoori@uokufa.edu.iq,khaled_tawil@ul.edu.lb, \\ hussainm.alshimmary@uokufa.edu.iq,nadhir.alansari@ltu.se,mjkplaner@gmail.com
}

How to cite this paper: Al-Maliki, L.A.J., Al-Mamoori, S.K., El-Tawel, K., Hussain, H.M., Al-Ansari, N. and Al Ali, M.J. (2018) Bearing Capacity Map for An-Najaf and Kufa Cities Using GIS. Engineering, 10, 262-269.

https://doi.org/10.4236/eng.2018.105018

Received: April 22, 2018

Accepted: May 19, 2018

Published: May 22, 2018

Copyright (c) 2018 by authors and Scientific Research Publishing Inc. This work is licensed under the Creative Commons Attribution International License (CC BY 4.0).

http://creativecommons.org/licenses/by/4.0/

\begin{abstract}
An-Najaf province is situated in south-western part of Iraq. It is 70 meters above the sea level in the dry desert environment. The city is considered as one of the most important cities in Iraq, facing a fast population growth and continuous development in constructions such as residential complexes, hotels, bridges and shopping malls. Soil investigation data for An-Najaf Province (An-Najaf and Kufa cities) from 464 boreholes drilled by the National Centre for Construction Laboratories \& Researches (NCCLR)/Babylon laboratory were used in this research. The data were analysed and possessed using Excel program then represented on the Geographical Information System (GIS) program by Inverse Distance Weighted (IDW) tool to create an allowable bearing capacity map for the soil at depths $0-2$ meters. The allowable bearing capacity is one of the most important soil characteristics to be considered when making a database for An-Najaf city soil. Geographical Information System GIS program enables to create reliable database for any characteristic and it is one of the best programs to produce an accurate map and allow ease in dealing with it. Those maps cover all the studied areas and by using contour lines, approximate values for no-data areas can be obtained. The results show that the allowable bearing capacity range is $5-20 \mathrm{Ton} / \mathrm{m}^{2}$ for both An-Najaf and Kufa cities. Kufa city has the range $5-9 \mathrm{Ton} / \mathrm{m}^{2}$. An-Najaf city has the range $7-18$ at the center, $8-10 \mathrm{Ton} / \mathrm{m}^{2}$ at the north eastern part, $7-14$ Ton $/ \mathrm{m}^{2}$ for the north western part, $6-12 \mathrm{Ton} / \mathrm{m}_{2}$ at the south eastern and 12 $19 \mathrm{Ton} / \mathrm{m}^{2}$ at the south western.
\end{abstract}




\section{Keywords}

Allowable Bearing Capacity, Geographical Information System GIS, AN-Najaf and Kufa Cities, Geotechnical Maps, Standard Penetration Test (SPT)

\section{Introduction}

The soil compressibility characteristic is very important when establishing any engineering structure. This compressibility is referred to as the bearing capacity of soil, which is the possibility of selecting the extent of dynamic and static loads without failure. Allowable bearing capacity is one of the important parameters used in deciding the engineering foundations [1]. The ability of a foundation to carry a load depends on the bearing capacity [2]. For any building to be constructed an extensive soil investigation must be carried out; this is a very strenuous, expensive and time-consuming task. Therefore, the need arose to minimize investigations as much as possible to meet the challenges of rapid expansion. Since soil exploration is too costly and mere guessing will not suffice when making foundations, this work suggests a quick way to over such engineering requirement [3].

The foundation is the supporting base of any structure which forms the interface across which the loads are transmitted to the underlying soil or rock [4]. The bearing capacity of soil is calculated from the standard penetration test (SPT) and core penetration test (CPT), or depends on engineering and physical properties obtained from test results for the samples in the laboratory [5]. The data of bearing capacity (B.C) in this study was calculated using a dynamic method, which depends on the standard penetration test (SPT). From the results of on-site that took the number of blows $(\mathrm{N})$ and got bearing capacity value depending on a formula. The bearing capacity depends on several factors such as soil quality, cohesion soil (fine-grained), cohesion less soil (coarse grained), and groundwater in addition to soil saturation condition, and wet and dry densities [6]. By knowing the bearing capacity for the soil, the type of foundations and its depths can be guessed, as well as improving soil properties to take the necessary precautions to avoid the damages especially from earthquakes [7]. This study included collecting, classification and analysis of the information for 464 boreholes in the study area and for depths $0,2,4,6,8,10,12,14,16$ and 35 meters. The data that were used in this research were taken from the National Center for Construction Laboratories \& Researches (NCCLR)/Babylon laboratory reports (NCCLR) [8]. Using GIS program abilities, a digital data base was made for the allowable bearing capacity. This can be generalized later to cover all soil properties and for all parts of Iraq, which enables to do the re-cyclization and treatment and analysis easily in making the designing and planning of any engineering project [9] [10].

This type of technique was used for Faisalabad region and proved to be fast 
and simple access to the information regarding foundation and allowable bearing capacity [11]. In addition, it was also used in other Iraqi provinces such as Baghdad, Diyala and Basra [10]. However, such a study has never been done with such a large amount of data, which gives greater accuracy to the results. Finally, such map will help in preliminary studies, feasibility studies, and land use policies.

\section{Methodology}

\subsection{The Study Area}

The governorate of An Najaf is located in south-western Iraq about $161 \mathrm{~km}$ southwest the capital Baghdad and it borders Saudi Arabia (Figure 1). It also shares internal boundaries with the governorates of Anbar, Kerbala, Babil, Qadissiya and Muthanna. Desert plains dominate the landscape of the governorate. It has an area of about $28,824 \mathrm{~km}^{2}$ which is approximately $7 \%$ of Iraq's total area [12]. The province comprising three districts: An-Najaf Center district (holly An-Najaf city, Kufa district and Al-Manathira district). This study cover parts of An-Najaf and Kufa districts and located between the coordinates $44^{\circ} 17^{\prime} 00^{\prime \prime} \mathrm{E}$ and $44^{\circ} 25^{\prime} 0^{\prime \prime} \mathrm{E}$ and $32^{\circ} 7^{\prime} 0^{\prime \prime} \mathrm{N}$ and $31^{\circ} \mathrm{N}$ [13]. An-Najaf city is located in Plateau region with an attitude of about $60 \mathrm{~m}$. Its slopes are flat and gradual toward the north, northwest, east, south east, and south, while its very steep and forming natural edge toward west and southern west [14]. The study area is consisting of successive rock formations from sedimentary origin [15].

An-Najaf province is located on the edge of the desert. It is located at the southwestern tip of the north section of the Mesopotamian plain and on the edge of the desert from the western side of the Euphrates River, which is $10 \mathrm{~km}$ away [16]. This site has been developed within the desert climate, which is characterized with a hot dry summer, cold winter and large difference in the daily temperature. The general direction of the wind is Northwest [13]. Summer temperatures rise to $34.70 \mathrm{C}, 33.70 \mathrm{C}$ and $36.70 \mathrm{C}$ in June, July and August respectively. The main reason for this is the angle of fall of the sun, which is semi-vertical, causing high intensity of solar radiation during summer. Temperatures decrease in winter, where it reaches $12.60 \mathrm{C}, 11.50 \mathrm{C}$ and $30 \mathrm{C}$ in December, January, and February respectively. This difference is due to the duration of solar radiation, where it reaches 11.9 hours per day in July while in December it is 5.7 hours/day. This variation resulted in a great thermal range between the summer and winter months and between night and day.

The rainfall in Najaf, like other cities in Iraq, follows the Mediterranean system. It increases in the winter and rare or absent during summer. Rainfall is restricted to the period from October to May and distributed unevenly. The total annual amount of annual rainfall is $101,112.3,121 \mathrm{~mm} / \mathrm{cm}^{2}$ [17]. An-Najaf city was chosen for this study because it is one of the largest and most important cities in Iraq, witnessing extensive urban development in the field of construction of multi-storey buildings and bridges. The results of this research will help 


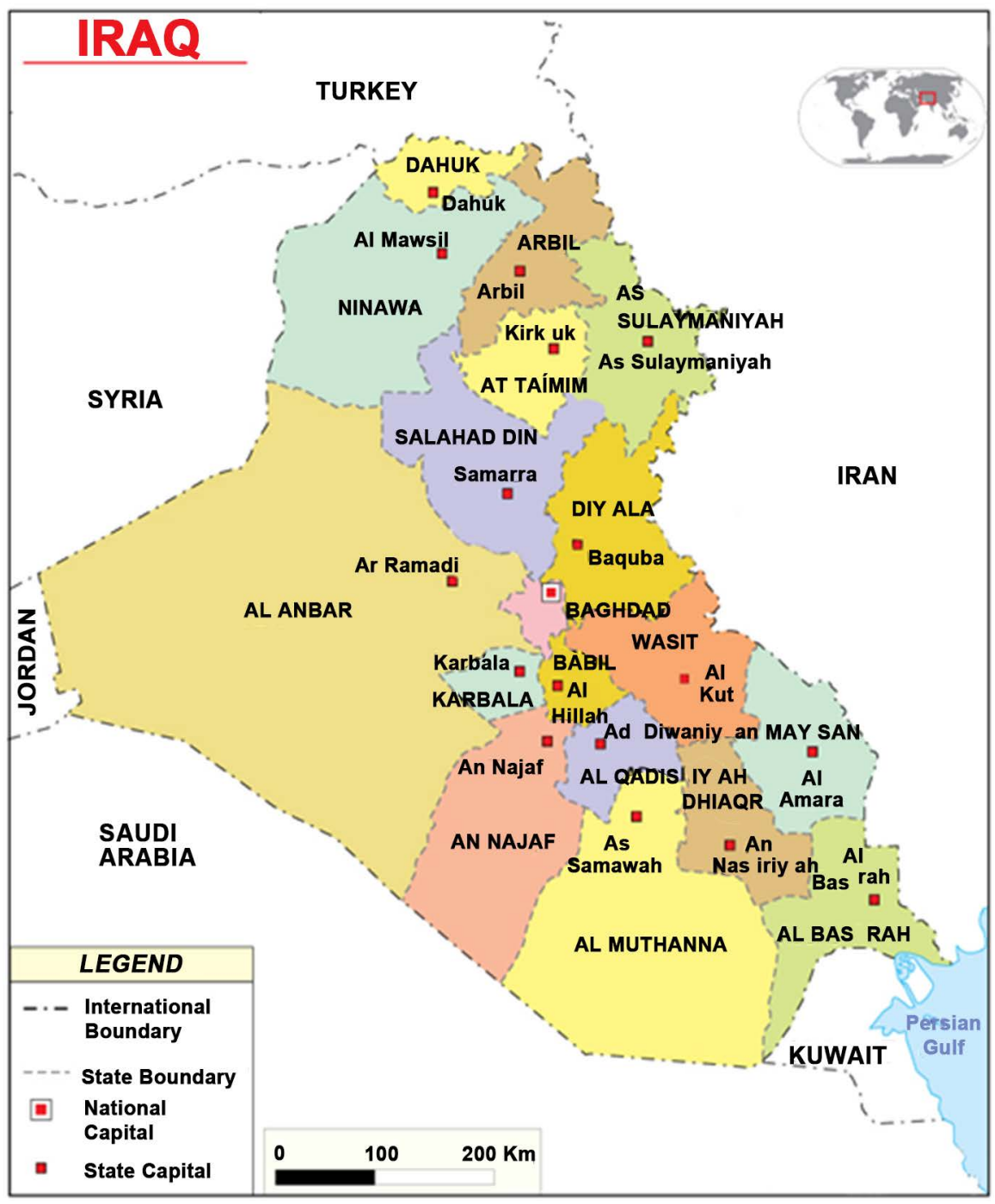

Figure 1. Location of An-Najaf province.

engineers and decision makers in Najaf to save time and cost needed to conduct the primary investigations.

\subsection{Data Collection}

The data used in this research was taken from the National Center for Construction Laboratories \& Researches (NCCLR)/Babylon laboratory reports. Babylon laboratory represents a branch of the National Center for Construction Laboratories \& Research (NCCLR), which is part of the Ministry of Construction and Housing. This laboratory is conducting the geotechnical tests for the Middle Euphrates region in addition to the testing of construction materials since its founding in 1977. After completion of all tests, soil is finally described in the light of these results. Then the layers were compiled together to find the bearing capacity of soil. It is usually calculated using the dynamic method from the results of in-suite N-SPT method for depth from $0 \mathrm{~m}$ to $2 \mathrm{~m}$ using Meyerhof for- 
mula 1965 [18] as follows:

$$
\text { qull }=N / 0.08[(B+0.3) / B]^{2}(1+0.33 D f / B)
$$

where:

$$
\begin{aligned}
& \text { qull = ultimate bearing capacity of soil } \\
& N=\text { No. of blows for SPT } \\
& B=\text { width of foundation, } \\
& D f=\text { depth of excavation of the footing }
\end{aligned}
$$

In addition, the groundwater level was recorded in the report where it was measured in situ after the completion of drilling, as well as directly after a period of 24 hours. The data were taking from 464 boreholes distributed in An-Najaf and Kufa cities and for depths of 0 - 2 meters. Locations of boreholes are shown in Figure 2. The coordinates of the boreholes have been obtained by GPS. The geotechnical maps were prepared using GIS program version 10.2.1.

\subsection{Software}

A Geographic Information System (GIS) program is designed to store, retrieve, manage, display, and analyse all types of geographic and spatial data. It can produce maps and other graphic displays of geographic information for analysis and presentation. To produce the bearing capacity maps, first the data were sorted and categorized in Excel files. This includes the name of the studied site and the site's features. It also has all the tables containing the data that were used

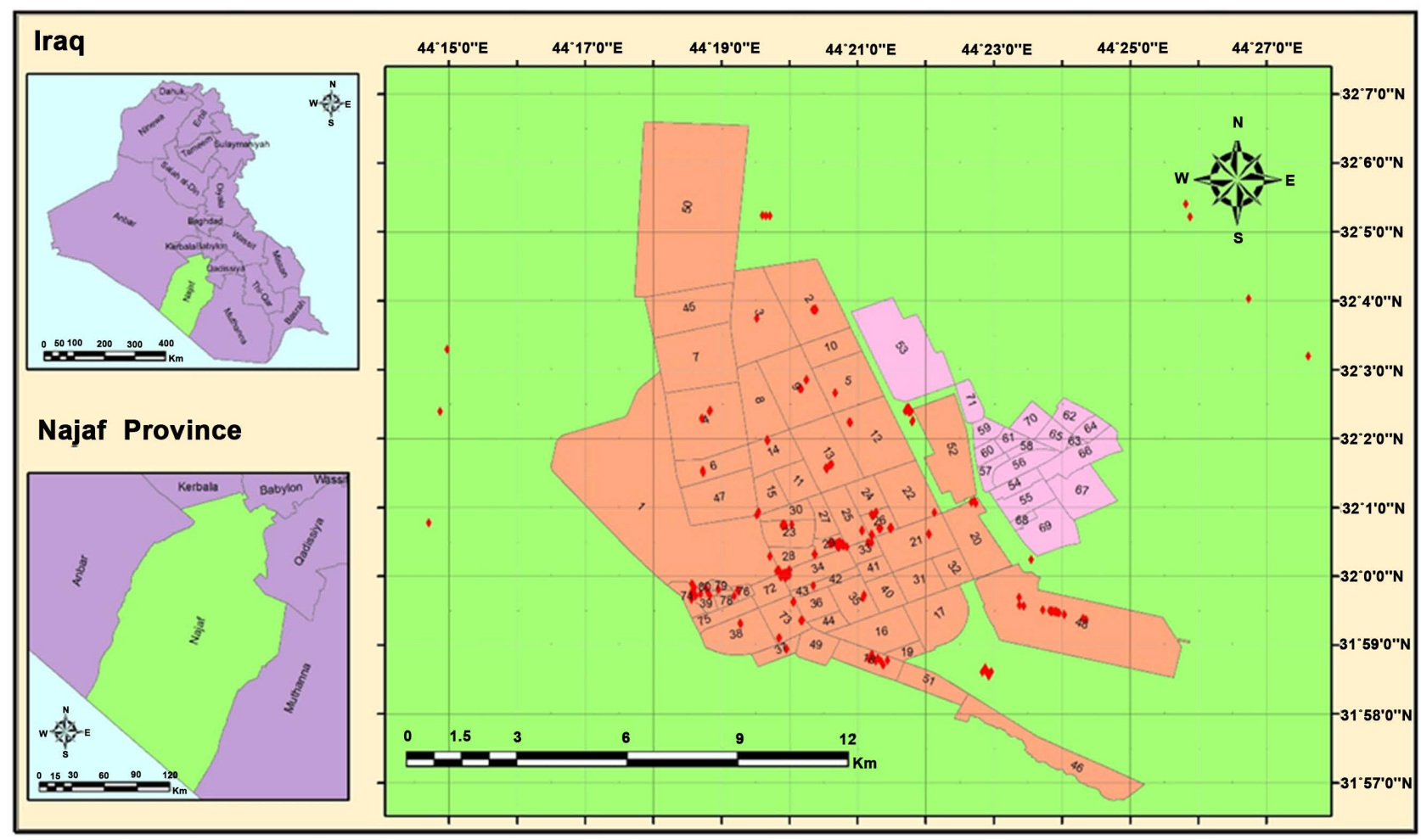

Figure 2. Locations of boreholes [10]. 


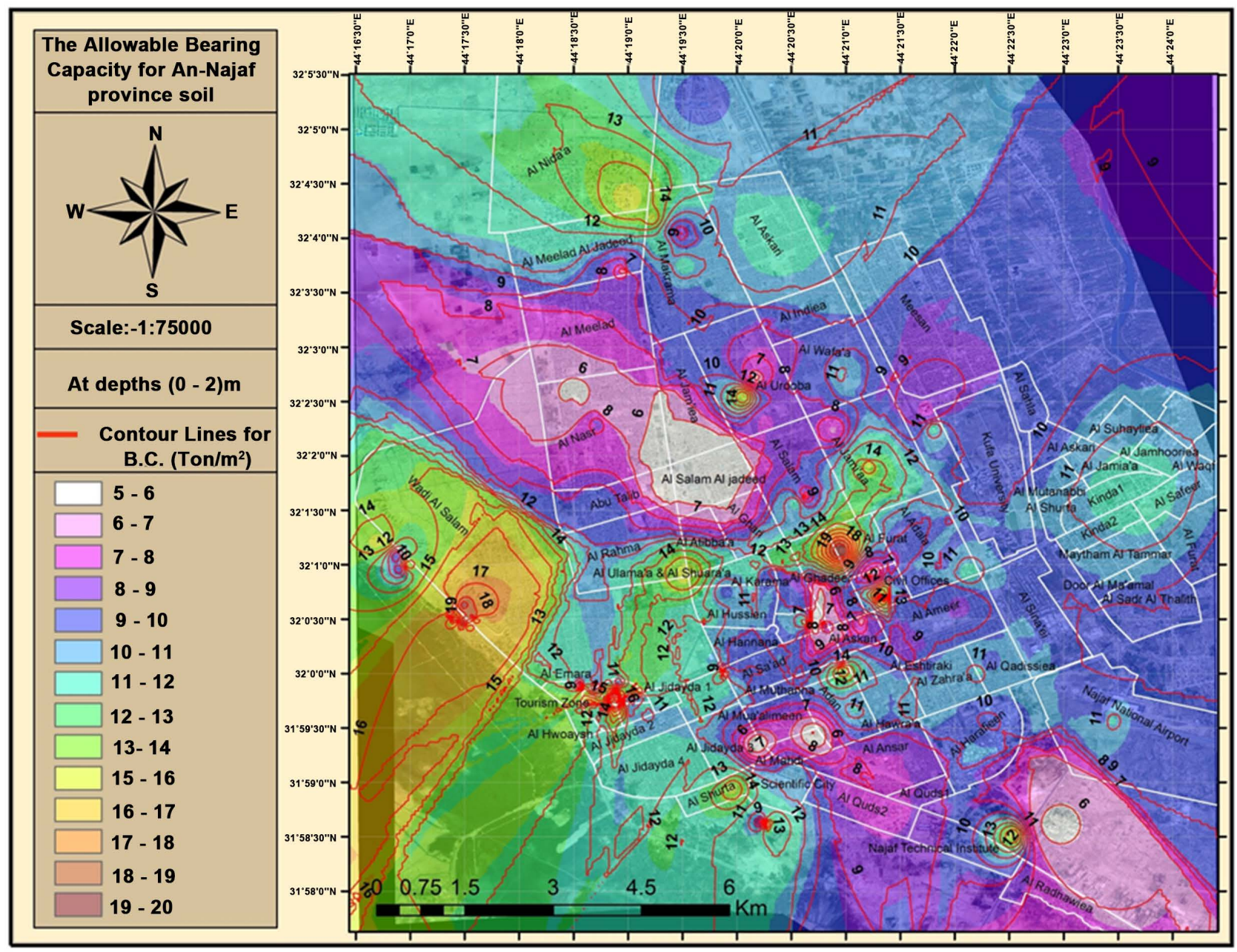

Figure 3. Allowable bearing capacity map for the study area.

in the analysis process. Then this file was used within the GIS (Arc-map) program for the purpose of data analysis and production of maps using a set of tools for this purpose. The GIS in its version (10.2.1) finally produced the bearing capacity geotechnical map.

\section{Results and Discussion}

The final map of allowable bearing capacity produced in Figure 3. In this map, the colour counters represent the bearing capacity for each neighborhood of the study area, where light colors indicate the lowest values while the dark colors indicate the highest values.

Figure 3 shows that the allowable bearing capacity for:

1) Najaf old city ranging between 11 to $16 \mathrm{Ton} \backslash \mathrm{m}^{2}$.

2) A.B.C in Wadi Al-salam (west of AN-Najaf) ranged between 10 to 18 Ton $\backslash \mathrm{m}^{2}$.

3) At the north of the study area, the results show that the allowable bearing capacity ranged between 6 to $14 \mathrm{Ton} \backslash \mathrm{m}^{2}$. While to the south, it ranged between 
(6 - 13) Ton $\backslash \mathrm{m}^{2}$.

4) The west region of the study area shows an allowable bearing capacity ranging between 10 to 11 Ton $\backslash \mathrm{m}^{2}$.

5) The highest results have emerged in Wadi Al-salam, while the lowest value emerged in Al-Salam Al-Jadeed neighborhood.

\section{Conclusions}

Using the information obtained from 464 soil test boreholes within the study area, an allowable bearing capacity map was constructed. This map can help in:

1) Using Geographic Information System (GIS) to produce geotechnical maps provides a helpful way to predict the allowable bearing capacity in non-Spatial data areas.

2) Geotechnical maps produced for the study area represent a very powerful database and visual display of the collected data. Besides, using these maps will help save time, cost and effort.

3) The produced maps can be used as a guidance for engineers and decisions makers to decide the suitability of any construction in the study area, the best foundation design and type of suitable treatment needed.

4) The allowable bearing capacity of the study area was ranging between 5 and 19 Ton $\backslash \mathrm{m}^{2}$.

5) This map can be used in the applications of smart cities.

\section{References}

[1] Kadhim, M.M., Al-Saoudi, N.K.S. and Ziboon, A.R. (2003) Digital Geotechnical Maps of Basrah City Using Geographical Information Systems Technique. Journal of Engineering \& Technology, 31, 599-617.

[2] Castelli, F. and Motta, E. (2012) Seismic Bearing Capacity of Shallow Foundations, Earthquake-Resistant Structures-Design, Assessment and Rehabilitation. In: Moustafa, A., Ed., InTech. https://www.tandfonline.com/doi/abs/10.1179/1939787915Y.0000000020

[3] Dungca, J.R., Concepcion Jr.I., Limyuen, M.C.M., See, T.O. and Vicencio, M.R. (2017) Soil Bearing Capacity Reference for Metro Manila, Philippines. International Journal of GEOMATE, 12, 5-11. https://doi.org/10.21660/2017.32.6556

[4] Atat, J.G., Akpabio, I.O. and George, N.J. (2013) Allowable Bearing Capacity for Shallow Foundation in Eket Local Government Area, Akwa Ibom State, Southern Nigeria. International Journal of Geosciences, 4, 1491-1500. https://doi.org/10.4236/ijg.2013.410146

[5] Terzaghi, K., Peck, R.B. and Mesri, G. (1996) Soil Mechanics in Engineering Practice. 3d Edition, John Wily and Sons. Inc., Hoboken.

[6] Freeze, R.A. and Chery, J.A. (1979) Groundwater. Prentice-Hall, Englewood Cliffs, 604.

[7] Santamarina, J.C. (2011) Soils and Waves: Particulate Materials Behavior, Characterization and Process Monitoring. John Wiley \& Sons, Hoboken.

[8] Faruq, R.H. and Khan, A.H. (2015) Mapping of Liquefaction Susceptible Sands of Punjab Province in Pakistan. Technical Journal, University of Engineering and 
Technology (UET) Taxila, Pakistan, 20, 74-84.

[9] National Center for Construction Laboratories \& Research (NCCLR) (2016) Investigation Reports. Governorate of Najaf, Iraq.

[10] Al-Shukriji, Y.J. and Al Khozai, A.M. (2011) The Geotechnical Maps for the Soil of the Governorates Baghdad, Diyala, Wasit And Babylon. Journal of Engineering, 17, 87-104.

[11] Al-Mamoori, S. (2017) Gypsum Content Horizontal and Vertical Distribution of An-Najaf and Al-Kufa Cities' Soil by Using GIS. Basra Journal of Engineering Sciences, 17, 48-60.

[12] Kamal, M.A., Arshad, M.U., Khan, S.A. and Zaidi, B.A. (2015) Appraisal of Geotechnical Characteristics of Soil for Different Zones of Faisalabad (Pakistan). Pakistan Journal Engineering and Applied Science, 17, 1-10.

[13] None Governmental Organization Coordination committee for Iraq (NCCI) (2015) Najaf Governorate Profile (In Arabic). NGO Coordination Committee for Iraq. https://www.tandfonline.com/doi/abs/10.1179/1939787915Y.0000000020

[14] El May, M., Souissi, D., Ben Said, H. and Dlala, M. (2015) Geotechnical Characterization of the Quaternary Alluvial Deposits in Tunis City (Tunisia). Journal of African Earth Sciences, 108, 89-100. https://doi.org/10.1016/j.jafrearsci.2015.05.003

[15] Yousif, B.F. (2004) The Use of Remote Sensing Techniques in the Classification of Al-Najaf Soil. M.Sc. Thesis, Building and Construction Engineering Department, University of Technology, Baghdad.

[16] Jassim, S.Z., and Goff, J.C. (2006) Geology of Iraq. Dolin, Prague and Moravian Museum Brno.

[17] Iraqi Ministry of Planning, Central Statistical Organization.

[18] Meyerhof, G.G. (1963) Some Recent Research on the Bearing Capacity of Foundations. Canadian Geotechnical Journal, 1, 16-31. https://doi.org/10.1139/t63-003 